\title{
Suppression Efficiency for Dust from an Iron Ore Pile Using a Conventional Sprinkler and a Water Mist Generator
}

\section{Yen-Yi Lee ${ }^{1,2,5}$, Chung-Shin Yuan ${ }^{3,4^{*}}$, Po-Hsuan Yen ${ }^{3}$, Justus Kavita Mutuku ${ }^{1,2,6^{*}}$, Chien-Er Huang ${ }^{1,2,7}$, Chih-Cheng $\mathrm{Wu}^{8}$, Po-Jen Huang ${ }^{8}$}

${ }^{1}$ Super micro mass research and technology center, Cheng Shiu University, Kaohsiung 833301, Taiwan

${ }^{2}$ Center for Environmental Toxin and Emerging-Contaminant Research, Cheng Shiu University, Kaohsiung 833301, Taiwan

${ }^{3}$ Institute of Environmental Engineering, National Sun Yat-sen University, Kaohsiung 80424,

Taiwan

${ }^{4}$ Aerosol Research Center, National Sun Yat-sen University, Kaohsiung 80424, Taiwan

${ }^{5}$ Department of Food and Beverage Management, Cheng Shiu University, Kaohsiung 833301, Taiwan

${ }^{6}$ Institute of Environmental Toxin and Emerging Contaminant, Cheng Shiu University, Kaohsiung 833301, Taiwan

${ }^{7}$ Department of Mechanical Engineering, Cheng Shiu University, Kaohsiung 833301, Taiwan

${ }^{8}$ Environmental Bioengineering and Chemical Analysis Section, New Materials Research and Development Department, China Steel Corporation, Kaohsiung 81233, Taiwan

\section{ABSTRACT}

Re-suspension of iron ore dust presents a constant hazard in the working environment within steel production plants. Herein, the optimal operating parameters for maximum dust suppression efficiencies through a water mist generator and a conventional sprinkler for particulate matter (PM) originating from an iron ore pile measuring about $2 \mathrm{~m}$ in height and with a stacking angle of about $30^{\circ}$ are investigated. The effects of operating parameters including wind velocity, spray angle, and mode of water supply on dust suppression efficiencies are evaluated. Size differentiated PM samples were collected from the upwind and downwind locations of the iron oral pile and the dust suppression efficiencies are determined. The operating parameters with the highest dust suppression efficiencies using the water mist technology are low spray angle, low wind velocity, and intermittent water supply, while those for water sprinkling technology are high spray angle, low wind velocity, and intermittent water supply. The average dust suppression efficiencies for Total Suspended Particles (TSP), $\mathrm{PM}_{10}$, and $\mathrm{PM}_{2.5}$ for the mist generators are $80.9 \%, 77.9 \%$, and $76.9 \%$, respectively, whereas those for the conventional sprinklers are $76.4 \%, 72.9 \%$, and $72.7 \%$, respectively. For the surfactant to water ratios of $0.024,0.022$ and no surfactant, the ratio of 0.024 had the highest dust suppression efficiencies for TSP, $\mathrm{PM}_{10}$, and $\mathrm{PM}_{2.5}$ at $90.9 \%, 89.5 \%$, and $89.0 \%$, respectively. Insights from this investigation can be applied to optimize the dust suppression methods to ensure economical consumption of water and energy.

Keywords: Iron ore pile, Particulate matter, Water mist generator and conventional sprinkler, Surfactant, Dust suppression efficiency

\section{INTRODUCTION}

In the operation of a steel plant, a significant concentration of particulate matter (PM) is emitted from the raw material storage site especially in the iron ore piles. These PM are characterized by 
a low height, temporal mass flow, and high concentrations are usually observed in the vicinity of the source (Ghose and Majee, 2002; Gladtke et al., 2009; Yadav et al., 2019). The concentration and particle size distribution of dust re-suspended from these raw material piles is important for assessing their health and environmental implications (Heinrich et al., 2002; Khan et al., 2010). Workers or residents in the regions neighboring raw material storage sites for steel plants usually suffer ill health, for instance, pneumoconiosis which is initiated by the accumulation of light dust particles in the alveolar region of the lungs (Cullinan and Reid, 2013; Humbal et al., 2018; Richardson et al., 2019; Kim et al., 2020). Dust resuspension is inevitable for most operations such as mining and industrial processes and it is mostly caused by the rolling or turbulence caused by air streams (Fu et al., 2013).

Aeolian process, refer to causes, impacts, and interactions of dust particles which are largely driven by, climate, combined surface properties, surface moisture, physical crusts, and disturbances (Ravi et al., 2011; Lu et al., 2017, 2018; Richardson et al., 2019). According to research on geophysical mechanisms, dust emission due to wind erosion is mostly caused by forces including aerodynamic entrainment, saltation bombardment and aggregates disintegration (Sweeney, 2020). The re-suspension force on the dust particles needs to exceed their binding potential for a successful transfer from the surface of the bulk particles to the dust phase.

To provide safe working environments to the workers in a steel plant as well as the residents neighboring the iron ore piles, it is necessary to put dust control measures including windshield, dust net, application of covers plant greening, sprinkling, and chemical spraying. These will in turn help to meet the Occupational Safety and Health Administration (OSHA) PM permissible exposure limits (PEL) of $15 \mathrm{mg} \mathrm{m}^{-3}$ and PM recommended exposure limits (REL) of about $1 \mathrm{mg} \mathrm{m}^{-3}$ (Kim and Sohn, 2016; Lin et al., 2019). This study focuses on sprinkling and mist generation technologies due to their low cost and high efficiency. The main drawback of sprinkling is the relatively large amount of water used which induces other disadvantages linked to severely waterlogged raw materials such as adhering to the conveyor belt during transportation and large energy consumption in the subsequent material processing. This drawback can be solved by applying mist generation technology to suppress fugitive dust. Mist generators apply high pressure to atomize water into droplets of diameter 10-50 $\mu \mathrm{m}$ (Krishnan et al., 2020; Wang and Jiang, 2021). Due to their small size, the mist droplets stay suspended for extended periods where they interact with PM via physical mechanisms including inertial impaction, direct interception, and diffusion. Attachment of PM on water droplets increases their mass causing them to settle under gravity and consequently lower the ambient PM concentrations.

Dust suppression through mist and sprinkler technology is mostly affected by two key factors including the efficiency of droplet-particle interaction in the gaseous phase and the physicochemical interactions succeeding the droplet-particle contact. To enhance the dust suppression efficiencies, carefully select wetting agents are applied which are mostly fatty alcohols including sodium hydroxide, urea, calcium chloride, ethyl alcohol, bischofite, sodium chloride and water. Most wetting agents have drawbacks such as unsanitary and unhygienic properties, strong corrosive effects on equipment, complex preparation methods, high cost, uncertainties about their effects on the human health, and low biodegradability (Zhang et al., 2020). Magnetite and hematite, which are the main ingredients of iron ore possess both hydrophobic and hydrophilic properties, other mineral compositions in iron ore are mostly hydrophilic and therefore, water can be applied as an appropriate wetting agent.

For study purposes, the concentrations of PM were measured at the upstream and downstream sections of the iron ore pile under three suppression scenarios including no intervention, application of a conventional water sprinkler, and application of a water mist generator. Different operating conditions were investigated including wind velocity, angle of spray, and mode of spraying (continuous or intermittent). The dust suppression efficiency and the optimum operation parameters for the water mist and conventional sprinkler dust suppression technologies were investigated.

A typical iron pile is presented in Fig. 1. The setup applied for this investigation includes industrial fans, an anemometer, a conventional sprinkler, a water mist generator, and filters for capturing the PM. The tests were performed in an outdoor open testing site within a steel plant. The goal was to determine the optimal operating parameters for dust suppression using a conventional water sprinkler and a water mist generator. For selected wind velocity, and water 


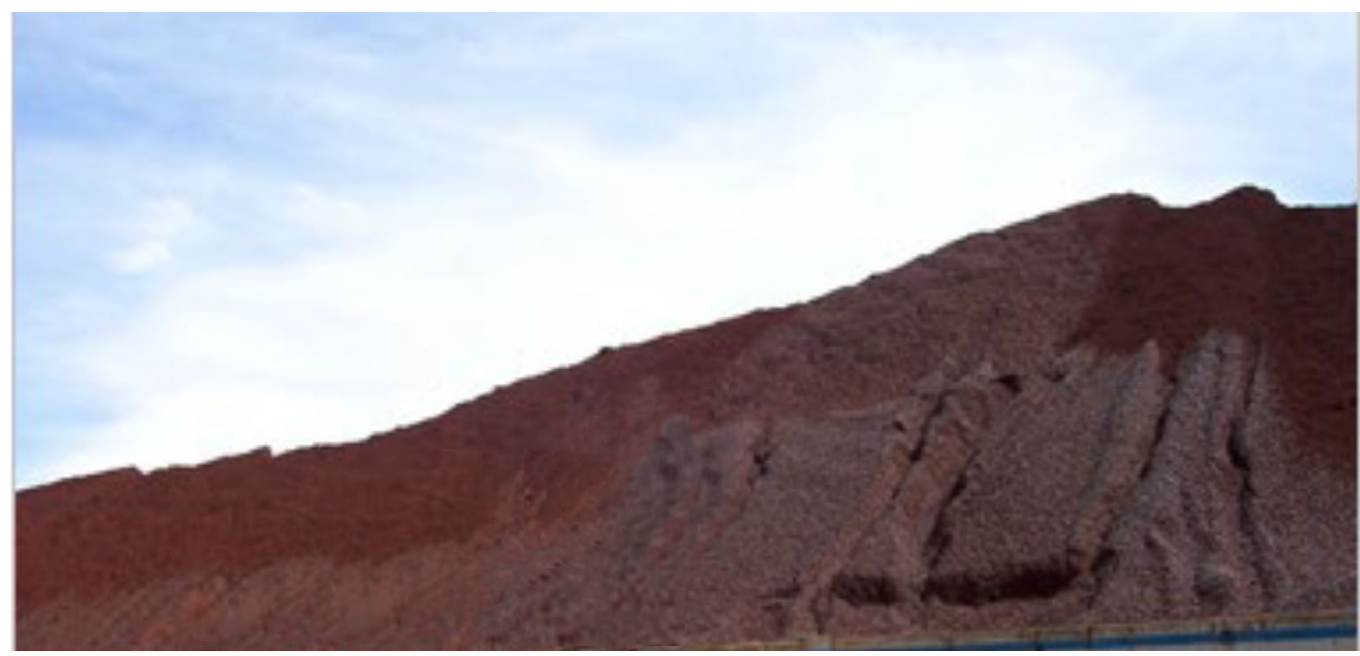

Fig. 1. Iron ore pile subjected to wind erosion at the raw material storage site.

or mist application conditions, the concentrations and size distribution of suspended PM in the upwind and downwind side of the iron ore pile were monitored. Thereafter, the effects of surfactants on dust suppression were further evaluated. Insights gained from this investigation can be applied to develop a dust suppression system and select its optimum operation parameters. Results obtained from this study can also assist in building an understanding of the effects of surfactants on dust suppression.

\section{METHODOLOGY}

The test site is in the China Steel Plant's raw material storage area with the dimension of $24 \mathrm{~m}$ by $15 \mathrm{~m}$. The relative positions of the industrial fans, the sprinkler, the water mist machine, and the PM samplers are illustrated in Fig. 2. In this research, three PM samplers are placed in a straight line in the north-south direction at the leeward position, with 1 meter away from the enclosure wall $7 \mathrm{~m}$ from the edge of the stockpile. Other three PM samplers are placed at the upwind position in the east-west direction, $2 \mathrm{~m}$ from the industrial fans. The spacing between PM samplers is $2 \mathrm{~m}$, and the frame holding the customized industrial fans is about $7 \mathrm{~m}$ by $1.5 \mathrm{~m}$ by $3.6 \mathrm{~m}$. It is placed $3 \mathrm{~m}$ from the stockpile.

\subsection{PM Sample Collection}

The standard method for fugitive TSP sampling, the Quasi-stack method, was applied in the area under investigation which was sealed to isolate a single pollution source. It is an upwinddownwind comparison method that uses mass balance of PMs to estimate the contribution of a specific intermediary pollution emission source. The main operating parameters applied in this study for dust suppression in the iron ore include wind velocity, whereby, the maximum daily wind velocity is obtained from the Kaohsiung Meteorological Station. In this research, low and high wind velocities are assumed to range between 1.6-3.3 and 8.0-10.7 $\mathrm{m} \mathrm{s}^{-1}$. Intermittent and continuous spraying methods are adopted for both the sprinkler equipment and the mist generating machine. The elevation angle is for the sprinkler and the water mist machine are adjusted to obtain different spray angles. The residual moisture content of the raw material is affected by the degree of evaporation and the duration of continuous water application. During this experiment, iron ore samples are simultaneously collected to measure the average moisture content of the iron ore surface $(2-5 \mathrm{~cm})$.

PM samplers including a TSP high-volume sampler (KIMOTO, 121FT), a $\mathrm{PM}_{10}$ high-volume sampler (TE, 6070), and a $\mathrm{PM}_{2.5}$ sampler (BGI, PQ-200) are applied to simultaneously measure the concentration of PM at the upwind and downwind sides of the iron ore pile. The TSP high-volume sampler is applied to collect total suspended particles (TSP) in the atmosphere, and it consists of four main parts including an air suction head, a filter holder, an air flowmeter, and a shelter. 


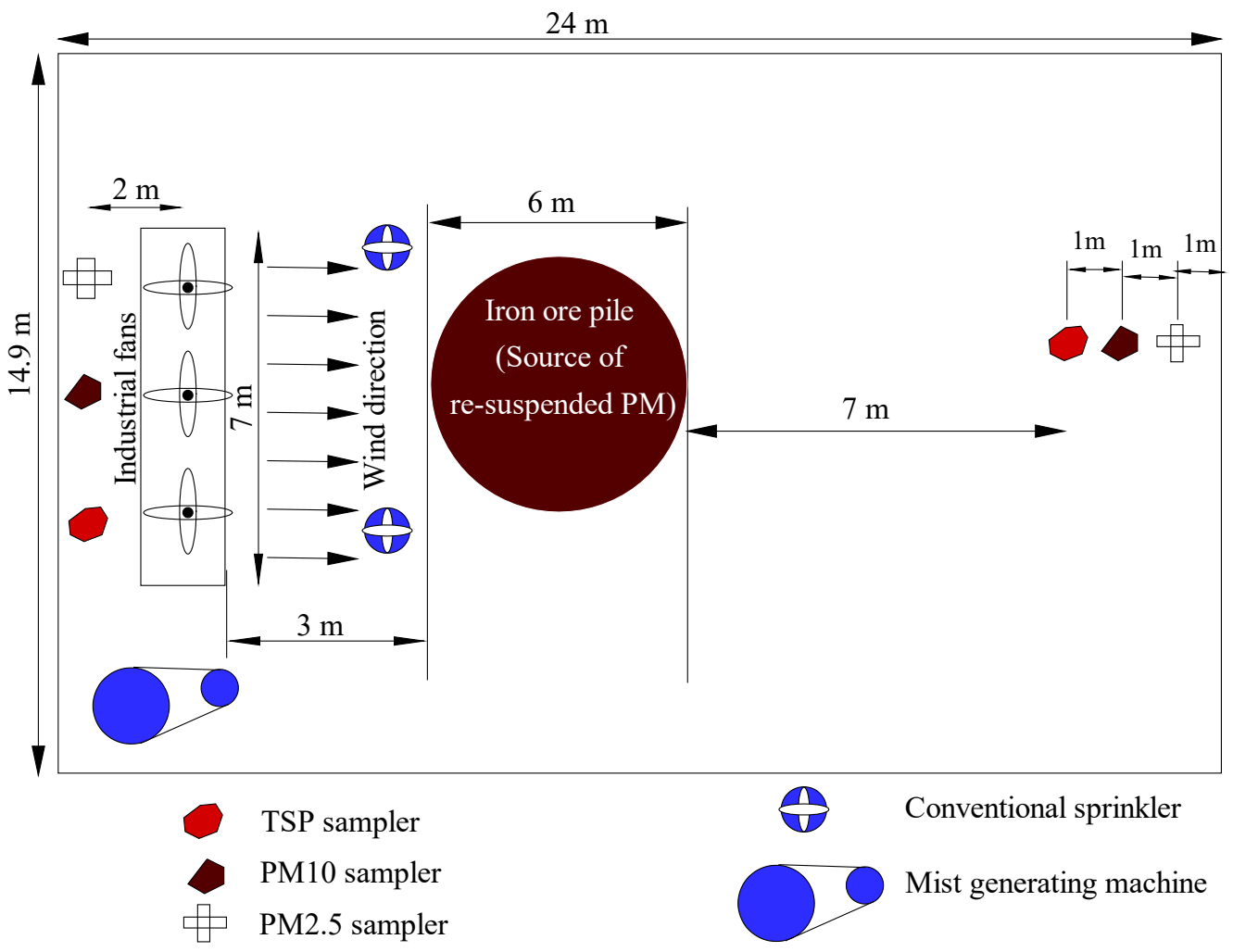

Fig. 2. Schematic diagram of the plan view of the implementation of up and down wind method in the test field.

Moreover, an air flowmeter and an orifice calibrator are applied to control the airflow rate. A column pressure gauge is used for airflow calibration, and the carbon brush of the air suction device needs to be replaced after about $400 \mathrm{hr}$ of usage. Filter paper $(20 \mathrm{~cm} \times 25 \mathrm{~cm})$ is placed on the filter holder during the TSP sampling operation. The fixed knob, which is locked diagonally, is checked to ensure no leakage. Care is exercised to ensure that the knob holding the filter paper in place is not locked too tightly as this might damage the filter paper causing potential leakage. A flow rate of 1.1-1.7 $\mathrm{m}^{3} \mathrm{~min}^{-1}$ sucks in the air and makes it pass through the quartz fiber filter to capture it. At this sampling flow rate, PM with a diameter of less than $100 \mu \mathrm{m}$ get sucked in and are intercepted by the filter paper. The concentration of TSP can be calculated by the following equations.

$C=\frac{\left(W_{f}-W_{i}\right)}{V} \times 10^{6}$

$V=\frac{\left(Q_{i}+Q_{f}\right)}{2} \times\left(t_{f}-t_{i}\right)$

where $C$ is the concentration of TSP $\left(\mu \mathrm{g} \mathrm{m}^{-3}\right), W_{i}$ is the weight of the filter after sampling $(\mathrm{g}), W_{f}$ is the weight of the filter before sampling $(\mathrm{g}), V$ is the total air volume $\left(\mathrm{m}^{3}\right), Q_{i}$ is the airflow rate at the beginning of sampling $\left(\mathrm{m}^{3} \mathrm{~min}^{-1}\right), Q_{f}$ is the airflow rate at the end of sampling $\left(\mathrm{m}^{3} \mathrm{~min}^{-1}\right)$, $t_{f}-t_{i}$ is the duration for TSP sampling (min).

The $\mathrm{PM}_{10}$ high-volume sampler is applied to collect suspended particles with the particle sizes of $10 \mu \mathrm{m}$ or less and it is composed of a filter holder, an air flowmeter, a cyclonic separator, and a shelter. The filter paper with an effective cross-sectional area of $18 \mathrm{~cm}$ by $23 \mathrm{~cm}$ and the suction airflow rate of 1.1-1.7 $\mathrm{m}^{3} \mathrm{~min}^{-1}$ is conditioned for $48 \mathrm{hr}$ or longer with constant temperature (20$25^{\circ} \mathrm{C}$ ) and relative humidity $(\mathrm{RH})(40 \pm 5 \%)$. A separator screen is used to allow PMs with aerodynamic 
diameter of $10 \mu \mathrm{m}$ or lower to be captured by the filter paper. The sampling duration and airflow rate of the $\mathrm{PM}_{10}$ samplers are recorded at the beginning and end, while the filter paper stored in a protective bag is sealed and stored in a dry place. Prior to weighing, the filter paper is conditioned at a constant temperature and relative humidity for $48 \mathrm{hr}$ or longer. The concentration of $\mathrm{PM}_{10}$ can be calculated by the following equations.

$$
\begin{aligned}
& C=\frac{\left(W_{e}-W_{s}\right)}{V} \times 10^{6} \\
& V=\frac{\left(Q_{s}+Q_{e}\right)}{2} \times t
\end{aligned}
$$

where $C$ is the concentration of $\mathrm{PM}_{10}\left(\mu \mathrm{g} \mathrm{m}^{-3}\right), W_{e}$ is the weight of the filter paper after sampling $(\mathrm{g}), W_{s}$ is the weight of the filter paper before sampling $(\mathrm{g}), V$ is the total air volume $\left(\mathrm{m}^{3}\right), Q_{s}$ is the airflow rate at the beginning of sampling $\left(\mathrm{m}^{3} \mathrm{~min}^{-1}\right), Q_{e}$ is the Gas production flow rate at the end of sampling $\left(\mathrm{m}^{3} \mathrm{~min}^{-1}\right)$, and $t$ is the duration for $\mathrm{PM}_{10}$ sampling (min).

The $\mathrm{PM}_{2.5}$ sampler is applied to collect PMs with an aerodynamic diameter of $2.5 \mu \mathrm{m}$ or less. The $\mathrm{PM}_{2.5}$ sampler is composed of an air inlet, an air duct, a very sharp cyclonic separator, a filter holder, an air sampling motor, an airflow controller, an air flowmeter, temperature monitors for environment and filter paper, an atmospheric pressure monitor, and a timer. To prevent the instrument from tipping over due to strong gusts, the $\mathrm{PM}_{2.5}$ sampler must firstly be fixed, and the sampling port elevated to above $2 \mathrm{~m}$. The $47 \mathrm{~mm}$ quartz fibrous filter is fixed in the filter holder and then connected to the air duct before sealing. Then the airflow is used to evenly pass through the filter paper, passing through the air inlet. The cyclonic separator screens particles with the aerodynamic diameter of $2.5 \mu \mathrm{m}$ or less. The concentration of $\mathrm{PM}_{2.5}$ can be calculated by the following equations.

$C=\frac{\left(W_{e}-W_{s}\right)}{V} \times 10^{6}$

$V=\frac{\left(Q_{s}+Q_{e}\right)}{2} \times t$

where $C$ is the concentration of $\mathrm{PM}_{2.5}\left(\mu \mathrm{g} \mathrm{m}^{-3}\right), W_{e}$ is the weight of the filter paper after sampling $(\mathrm{g}), W_{s}$ is the weight of the filter paper before sampling $(\mathrm{g}), V$ is the total air volume $\left(\mathrm{m}^{3}\right), Q_{s}$ is the airflow rate at the beginning of sampling $\left(\mathrm{m}^{3} \mathrm{~min}^{-1}\right), Q_{e}$ is the airflow rate at the end of sampling $\left(\mathrm{m}^{3} \mathrm{~min}^{-1}\right)$, and $t$ is the duration for $\mathrm{PM}_{2.5}$ sampling ( $\mathrm{min}$ ).

A handheld portable particle monitor (Aerocet, 531S) shown in Fig. 3(a) is applied to measure the dust rise at the downwind of the sampling area. The change in the concentration of PMs is measured every $15 \mathrm{~min}$. A laser diode is used as the light source which transmits PMs in the air through forward scattering to a photodetector. The resultant photoelectric effect generates a current which is then amplified through a photomultiplier tube. The concentrations of PMs with different size ranges (i.e., $\mathrm{PM}_{1}, \mathrm{PM}_{2.5}, \mathrm{PM}_{4}, \mathrm{PM}_{7}, \mathrm{PM}_{10}$, and TSP) are measured and converted to mass concentrations whereby, the measurement time is 2 min for the suitable PM concentration range of $0-1000 \mu \mathrm{g} \mathrm{m}^{-1}$.

\subsection{Wind Source and Velocity Measurement}

Industrial fans are assembled to provide a uniform and stable wind field as outlined in earlier publication (Yen et al., 2021). The design width of the fan unit must cover the entire diameter range of the pile. After the angle of repose of the iron ore pile, set the bottom diameter of the pile to be about $7 \mathrm{~m}$, and the height of the industrial fan assembled to a higher vertical height than that of iron ore pile $(2.4-2.7 \mathrm{~m})$. The maximum size of the grid is about $1.25 \mathrm{~m}$, which is not enough to cover our experimental field, therefore, fans are stacked in two layers to achieve a sufficient height. The control switch system adopts the design of stepless frequency converter to 
(a)

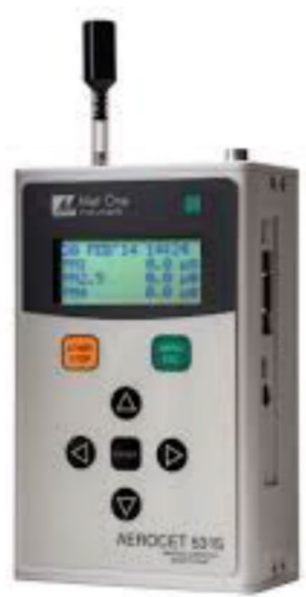

(b)

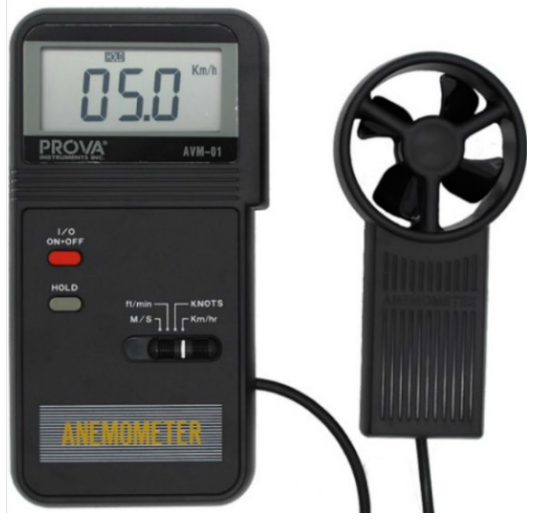

Fig. 3. Pictures of (a) Handheld portable particle monitor (Aerocet, 531S) and (b) Anemometer (AVM-01)

facilitate the adjustment of the simulated wind velocity. The structure supporting the industrial fans made of stainless steel is rigid and rustproof. The control switch box is waterproof to prevent short circuiting, and the frequency converter uses stepless frequency converter, and has an ip55 rating protection again dust and water droplets.

An anemometer (AVM-01) shown in Fig. 3(b) is used to measure the wind velocities while the dust concentration was evaluated. Prior to drawing the wind field map, the anemometer with four-blades is applied to measure the wind velocity range of $0-45 \mathrm{~m} \mathrm{~s}^{-1}$ with the accuracy of \pm 0.3 $\mathrm{m} \mathrm{s}^{-1}$. In this investigation, eight fans are adjusted to the same velocity and the anemometer was placed $3 \mathrm{~m}$ in front of the fans. After the wind velocity reading on the anemometer is stably constant, for instance between 1-10 $\mathrm{m} \mathrm{s}^{-1}$, the corresponding fan rotation velocity and the anemometer reading are plotted as shown in Fig. 4. The fans are adjusted to two different wind velocities of 3 and $10 \mathrm{~m} \mathrm{~s}^{-1}$. Fast measurement is performed in an interval of $30 \mathrm{~s}$ whereby the data is recorded every $5 \mathrm{~s}$ and the average data is taken to represent the wind velocities at the heights of 1 and $2 \mathrm{~m}$ above the ground, respectively. All the tests are performed on April $16^{\text {th }}$, 2020 , whereby a north wind was dominant with an average wind velocity of $1.2 \mathrm{~m} \mathrm{~s}^{-1}$. Although the test site is located outdoors, it is surrounded by an industrial fence and therefore had insignificant influence from the external wind fields.

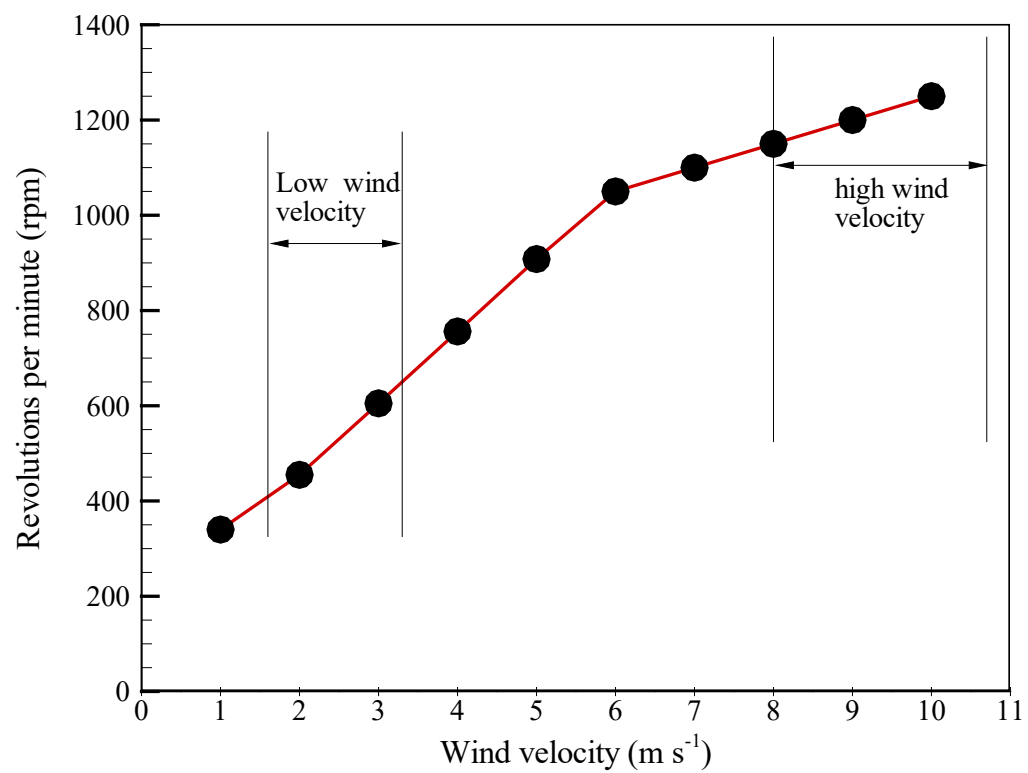

Fig. 4. A plot of wind velocity in the test field against the rotations per minute on the anemometer. 
Table 2. Properties of the mist generator and the conventional sprinkler.

\begin{tabular}{lll}
\hline Specifications of the Equipment & Mist Generation Machine & Conventional Sprinkler \\
\hline Pressure & $290-1450 \mathrm{psi}$ & $30-75 \mathrm{psi}$ \\
Spray radius & $50 \mathrm{~m}$ & $8-12 \mathrm{~m}^{-1}$ \\
Spray water & $150 \mathrm{~L} \mathrm{~min}^{-1}$ & $20-25 \mathrm{~L} \mathrm{~min}^{-1}$ \\
Rotation angle & $0^{\circ}-179^{\circ}$ & $50^{\circ}-360^{\circ}$ (adjustable) \\
Spray elevation & $-10^{\circ}-90^{\circ}$ & $0^{\circ}-90^{\circ}$ (adjustable) \\
\hline
\end{tabular}

\subsection{Mist Generation Device and Conventional Sprinkler for Dust Suppression}

The descriptions of the water mist machine applied for this study have been presented in the earlier study (Yen et al., 2021). The water mist machine uses a high-pressure pump to atomize the micro-droplets of water, a fan and a divergent nozzle to blow the fine mist passing over long distances using a strong wind. The settling of fine mist under the gravity force is highly unlikely and as such can remain it airborne for a longer time than ordinary water droplets.

The second device uses the conventional water sprinkler to suppress fugitive dust, where a motor pressurizes water through an aluminum alloy metal sprinkler head, forming a water flow rate of 20-25 L min-1. The water droplets cover a large area of the iron ore pile, humidify the surface of iron ore pile on its front side, and prevent the re-suspension of dust caused by wind erosion. The specifications of the sprinkler are detailed in Table 2, where the bottom of the sprinkler head is connected to the 1/2-inch female adapter and a customized sprinkler tripod stand which is $50 \mathrm{~cm}$ in height and $3.5 \mathrm{~kg}$ in weight. A 1/2-horsepower motor with an on-off control valve at the outlet is used to control the pressure (Yen et al., 2021). A summary of the operation parameters of the two watering measures for dust suppression are presented in Table 2.

For both devices, the mechanism of dust suppression using water mist/droplets applies three mechanisms including inertial impaction, direct interception, and diffusion. The water mist/droplets accumulate PM, grow in mass, and eventually settle down under gravity. Additionally, upon impaction on the surface of the pile, it makes the pile moist and prevents the resuspension of dust through wind erosion.

\section{RESULTS AND DISCUSSION}

When the sum of friction and attraction between dust particles is less than the carrying force of the wind, the particles could be accelerated and moved with the wind. According to Bagnold et al. (1977), critical friction velocity refers to the threshold friction velocity required to cause dust particles to rise up, which can be expressed by the following equation.

$u^{\prime}=k\left[\frac{d \times g \times \rho_{s}}{\rho}\right]^{\frac{1}{2}}$

where $u^{\prime}$ is the critical friction velocity $\left(\mathrm{m} \mathrm{s}^{-1}\right), k$ is a coefficient, $d$ is the particle diameter $(\mu \mathrm{m}), g$ is the acceleration due to gravitational field $\left(9.81 \mathrm{~m} \mathrm{~s}^{-2}\right), \rho_{s}$ is the density of particles $\left(\mathrm{kg} \mathrm{m}^{-3}\right)$, and $\rho$ is the air density $\left(\mathrm{kg} \mathrm{m}^{-3}\right)$.

From the expression, particle size and specific gravity are positively correlated to the critical wind velocity, implying that the heavier the dust particles, the higher the wind velocity required to raise them up. Generally, the critical friction velocity for street dust to be raised by the wind speed is about $5.38 \mathrm{~m} \mathrm{~s}^{-1}$ for particles with an aerodynamic diameter of $26 \mu \mathrm{m}$ or less. As the wind velocity exceeds $6.0 \mathrm{~m} \mathrm{~s}^{-1}$, the amount of fugitive dust increases exponentially (McKennaNeuman and Nickling, 1989).

\subsection{Variation of Suspended PM Concentration with Wind Velocity}

For this investigation, the wind velocity is gradually increased from 0 to $10 \mathrm{~m} \mathrm{~s}^{-1}$ at a rate of $1 \mathrm{~m} \mathrm{~s}^{-1}$ per min. The concentrations of $\mathrm{PM}_{2.5}, \mathrm{PM}_{10}$, and TSP at the downstream end of the fans 
are obtained under different wind velocities ranging from 0 to $3 \mathrm{~m} \mathrm{~s}^{-1}$, where they were $9.7,62.2$, and $99.1 \mu \mathrm{g} \mathrm{m}^{-3}$, respectively, while those at the wind speeds ranging from 3 to $10 \mathrm{~m} \mathrm{~s}^{-1}$ were $18.7,196.1$, and $248.4 \mu \mathrm{g} \mathrm{m}^{-3}$, respectively. At the wind speed up to $10 \mathrm{~m} \mathrm{~s}^{-1}$, the proportions of $\mathrm{PM}_{2.5}, \mathrm{PM}_{2.5-10}$, and $\mathrm{PM}_{10}-\mathrm{TSP}$ were $4.5 \%, 71.4 \%$, and $21.0 \%$, respectively. Therefore, for iron ore pile at a wind velocity of $10 \mathrm{~m} \mathrm{~s}^{-1}$, the resuspended PM is predominantly $\mathrm{PM}_{2.5-10}$.

As illustrated in Fig. 5, the higher the wind velocity, the higher the concentration of fugitive dust, where there is a linear upward trend for iron ore pile. This agrees with previous investigations in the USA on $\mathrm{PM}_{10}$ pollution which exposed the main emission source as for the re-suspension of street dust and vehicular exhausts (Watson and Chow, 2001; Chow et al., 2003; Ho et al., 2003; Chow et al., 2004). The $\mathrm{PM}_{10}$ suppression technologies currently applied are susceptible to the atmospheric conditions including wind velocity, wind direction, solar radiation, and air temperature.

In this study, the linear relationship between the wind velocity and the fugitive dust concentrations including $\mathrm{PM}_{1}, \mathrm{PM}_{2.5}, \mathrm{PM}_{4}, \mathrm{PM}_{7}, \mathrm{PM}_{10}$, and TSP are represented by the linear regressions of the form $Y=a X^{2}+b X+c$ as summarized in Table 3 . To reduce energy consumption, the water mist technology and the dust suppression efficiency are performed regularly and quantitatively.

Furthermore, to correlate the operating parameters under investigation in this test to the dust suppression efficiency, the differences between the measurement data at the upwind dust concentration and the measured downwind dust concentration (N-B) are initially quantified. The

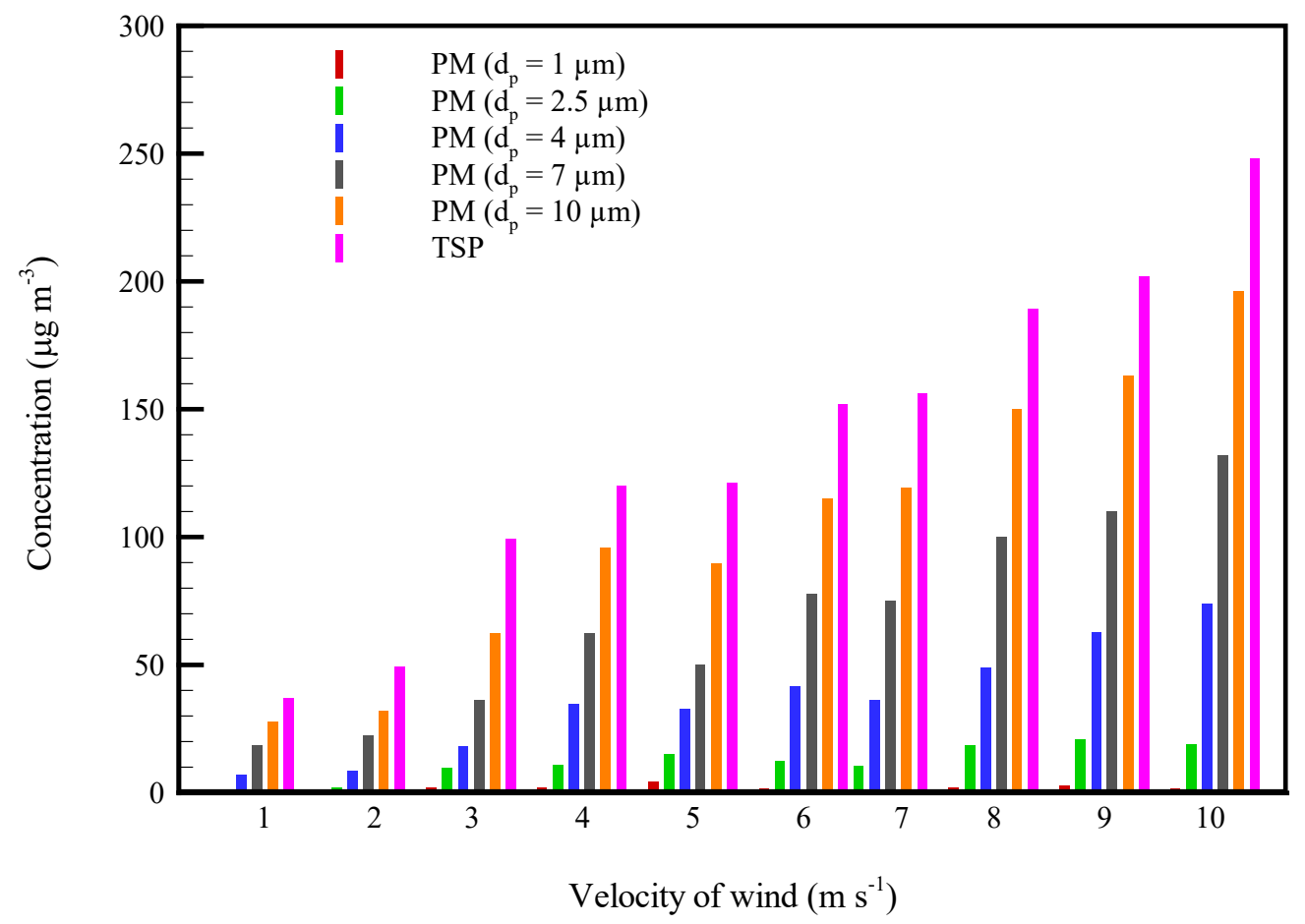

Fig. 5. Concentration of fugitive dust re-suspended from the of iron ore pile with different wind velocities.

Table 3. Regression equations of the concentration of suspended particulates in different stockpiles and environmental wind velocity.

\begin{tabular}{lllll}
\hline & Types of Piles & & \multicolumn{2}{c}{ Iron Ore Pile } \\
\cline { 1 - 2 } Coefficients & $\mathrm{a}$ & $\mathrm{b}$ & $\mathrm{c}$ \\
\hline $\mathrm{PM}_{1}$ & -0.075 & 0.965 & -0.482 \\
$\mathrm{PM}_{2.5}$ & -0.143 & 3.584 & -2.337 \\
$\mathrm{PM}_{4}$ & 0.186 & 4.919 & 2.149 \\
$\mathrm{PM}_{7}$ & 0.417 & 7.666 & 10.255 \\
$\mathrm{PM}_{10}$ & 0.217 & 15.587 & 10.879 \\
TSP & 0.029 & 21.295 & 19.179 \\
\hline
\end{tabular}


control values $E$ and $C B$ are the measured background concentration of $P M$ perform only once, where no dust suppression mechanism is applied. The overall dust suppression efficiency is calculated using the following equation.

$\eta_{i}=\frac{E-\left(N_{i}-B_{i}-C B\right)}{E} \times 100 \%$

where $\eta_{i}$ is the suppression efficiency of dust for iron ore pile (\%), $E$ is the concentration of fugitive dust $\left(\mu \mathrm{g} \mathrm{m}^{-3}\right), N_{i}$ is the uncontrolled PM concentration at the downwind site $\left(\mu \mathrm{g} \mathrm{m}^{-3}\right), B_{i}$ is the background PM concentration at the upwind site $\left(\mu \mathrm{g} \mathrm{m}^{-3}\right), C B$ is the controlled background PM concentration $\left(\mu \mathrm{g} \mathrm{m}^{-3}\right)$.

Aeolian processes caused by human activities, geological, and prevailing weather conditions have deleterious effects on human respiratory health by causing substantial surges in respirable dust (Ravi et al., 2011). According to previous studies, PMs with smaller particle diameters are preferably carried over longer distances through advection and turbulent dispersion and later fall to the ground by wet or dry deposition mechanisms (Wang et al., 2019). Herein, the adverse is true as shown in Fig. 5 and this is due to particle size distribution of the iron ore, whereby the TSP are in higher concentrations compared to course and fine particles (i.e., $\mathrm{PM}_{2.5-10}$ and $\mathrm{PM}_{2.5}$ ) (Sweeney, 2020).

\subsection{Dust Suppression Efficiency using Water Mist Technology}

Water mist/droplets were atomized intermittently or continuously using either the mist generating machines or the sprinklers at different angles with different wind velocities to explore the impact of operating conditions on the dust suppression efficiency. The results for dust suppression using water mist technology at a low angle with different wind velocities are illustrated in Fig. 6(a). The test results indicate that for the water mist technology, under continuous water supply at high wind velocity of $10 \mathrm{~m} \mathrm{~s}^{-1}$, the dust suppression efficiencies of TSP, $\mathrm{PM}_{10}$ and $\mathrm{PM}_{2.5}$ are $78.2 \%, 75.0 \%$, and $70.8 \%$, respectively, while those at low wind velocity of $3 \mathrm{~m} \mathrm{~s}^{-1}$ are $81.1 \%$, $78.7 \%$, and $76.9 \%$, respectively. This implies that under continuous water supply mode, low wind velocity gives more favorable dust suppression efficiencies for particles of all diameters under investigation. Furthermore, in Fig. 7(b), at a high angle of spraying, the test results show that in the case of high wind velocity, the water mist machine provides continuous water supply the suppression efficiencies of $\mathrm{TSP}, \mathrm{PM}_{10}$, and $\mathrm{PM}_{2.5}$ are $77.8 \%, 73.9 \%$, and $69.1 \%$, respectively. On the other hand, in low wind velocity conditions, under continuous water supply, the suppression efficiencies of $\mathrm{TSP}, \mathrm{PM}_{10}$, and $\mathrm{PM}_{2.5}$ are $78.4 \%, 76.1 \%$, and $73.5 \%$, respectively. The overall trend shows that for continuous water supply mode, the dust suppression with low angle of spraying is applied exceeded that for a high angle of spray for both low and high wind velocities.

For intermittent water supply mode, in the case of low angle spraying at high wind velocity, the suppression efficiencies of TSP, $\mathrm{PM}_{10}$, and $\mathrm{PM}_{2.5}$ are $81.3 \%, 78.2 \%$, and $77.4 \%$, respectively, while in the case of low wind velocity, the suppression efficiencies of TSP, $\mathrm{PM}_{10}$, and $\mathrm{PM}_{2.5}$ are $86.4 \%, 83.1 \%$, and $86.8 \%$. Under intermittent water supply and high angle of spraying, the suppression efficiencies of $T S P, \mathrm{PM}_{10}$, and $\mathrm{PM}_{2.5}$ at high wind velocity are 79.6, 77.4, and 76.1\% respectively, while the suppression efficiencies of TSP, $\mathrm{PM}_{10}$, and $\mathrm{PM}_{2.5}$ under the low angle of spraying are $84.6 \%, 80.6 \%$, and $84.3 \%$, respectively.

According to the above test results, the overall average suppression efficiency of fugitive dust using the mist generator as the dust suppression mechanism ranks as follows; TSP $>\mathrm{PM}_{10}>\mathrm{PM}_{2.5}$, where TSP is $80.9 \%$ with the range of $77.8-86.4 \%, \mathrm{PM}_{10}$ is $77.9 \%$ with the range of $75.0-83.1 \%$, and $\mathrm{PM}_{2.5}$ is $76.9 \%$ with the range of $69.1-86.8 \%$. Under the influence of different wind velocities, the average suppression efficiency of fugitive dust at low wind velocity is $80 \%$, while that at high wind velocity is $76 \%$. The suppression efficiency of fugitive dust at low-angle spraying (81\%) is better than that at high-angle spraying (78\%). Under intermittent water supplying, the average suppression efficiency of fugitive dust is $81 \%$ and it exceeded that of continuous water supply at $76 \%$. The fine droplets sprayed by the water mist technology are evenly distributed in the air stream under the influence of wind flow. Additionally, it wets the surface of the iron ore pile preventing dust from resuspension (Faschingleitner and Höflinger, 2011). 

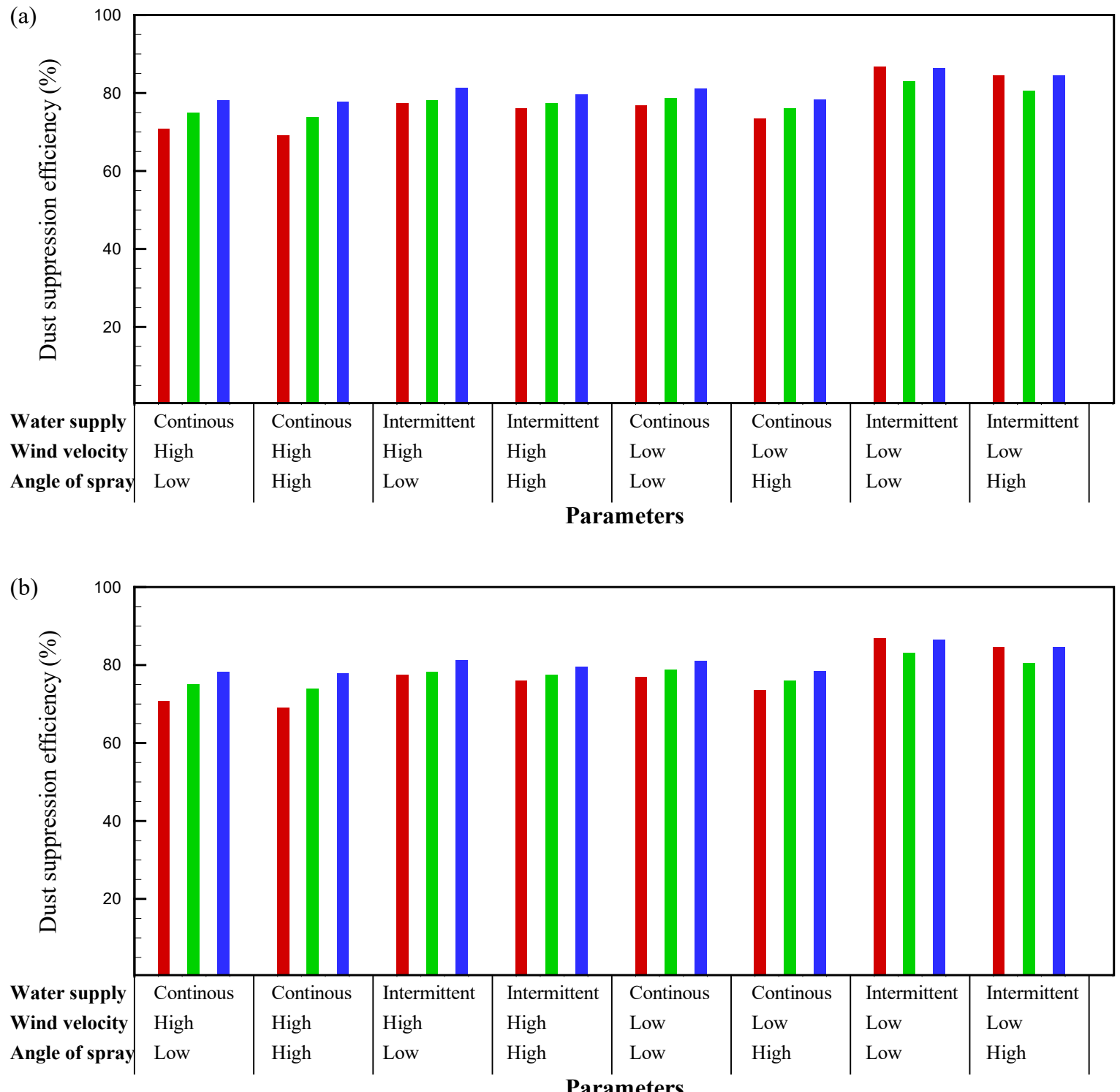

Fig. 6. Suppression efficiency of dust re-suspended from iron ore piles using (a) mist generators and (b) conventional sprinklers.

Overall, the water mist machine can effectively suppress TSP, $\mathrm{PM}_{10}$, and $\mathrm{PM}_{2.5}$, and the best performance is obtained at low wind velocity, low angle spraying, and intermittent water supply as shown in Fig 6(a). This is because spraying at low angles, the small and light water droplets easily change their motion under the influence of air stream, get evenly distributed over the entire surface of the iron ore pile and avoid the resuspension of dust caused by strong wind, which is called the primary dust minimization. Additionally, the secondary dust minimization at low-angle spraying is relatively high since water droplets sprayed by the water mist generation machine are small and light. Thus, their motion easily changes under the influence of wind velocity and evenly distributes to cover the entire raw material pile (Faschingleitner and Höflinger, 2011). As the mist generation technology is applied, the dust suppression efficiency using low-angle spraying $>$ highangle spraying; that of low wind velocity > high wind velocity; and that of intermittent water supply mode $>$ continuous water supply mode. The optimal operating parameters are similar to previous investigation on coal pile, but its suppression efficiency of fugitive dust emitted from coal pile (80\%) is slightly higher than that from iron ore pile (78\%) (Yen et al., 2021).

\subsection{Dust Suppression Efficiency using Conventional Sprinklers}

As shown in Fig. 6(b), the dust suppression efficiencies under continuous water supply, different 
spraying angles, and wind velocities are displayed. In the case of continuous water supply and low-angle spraying with high wind velocity, the suppression efficiencies of TSP, $\mathrm{PM}_{10}$, and $\mathrm{PM}_{2.5}$ are $73.5 \%, 70.9 \%$, and $67.1 \%$, respectively, while those with low wind velocity and low-angle spraying are $76.9 \%, 74.7 \%$, and $72.8 \%$, respectively. Furthermore, under high-angle spraying and high wind velocity, the suppression efficiencies of $\mathrm{TSP}, \mathrm{PM}_{10}$, and $\mathrm{PM}_{2.5}$ are $75.6 \%, 73.7 \%$, and $70.3 \%$ respectively, while those under low wind velocity are $78.2 \%, 74.3 \%$, and $71.8 \%$, respectively.

On the other hand, for the intermittent water supply, at low-angle spraying, in the case of high wind velocity, the suppression efficiencies of TSP, $\mathrm{PM}_{10}$, and $\mathrm{PM}_{2.5}$ are $72.4 \%, 70.8 \%$, and $69.2 \%$, respectively, while under low wind velocity conditions they are $79.5 \%, 73.6 \%$, and $76.8 \%$, respectively. At high-angle spraying and high wind velocity, the suppression efficiencies of TSP, $\mathrm{PM}_{10}$, and $\mathrm{PM}_{2.5}$ are $77.1 \%, 74.3 \%$, and $70.5 \%$, respectively, while those at low wind velocity are $82.1 \%, 76.8 \%$, and $78.9 \%$, respectively. It concludes that lower wind velocities provide sufficient time for fine mist/droplets to interact with dust particles and envelope them; hence resulting in higher dust suppression efficiencies (Xu et al., 2018).

According to the above test results, the averages (ranges) of dust suppression efficiencies for TSP, $\mathrm{PM}_{10}$, and $\mathrm{PM}_{2.5}$ using sprinkler technology are $76.9 \%$ (72.4-82.1\%), 73.6\% (70.8-76.8\%), and $72.2 \%$ (67.1-78.9\%) at high wind velocities, while those for low wind velocities are 76.0, 72.1, and $73.2 \%$. Furthermore, high-angle spraying is more efficient in dust suppression compared to low-angle spraying. The average dust suppression efficiency of $75.2 \%$ for intermittent water supply is superior to that of $73.3 \%$ for continuous water supply. It is attributed to the fact that water droplets sprayed by the sprinklers are larger and heavier compared to those by mist generators and cannot be easily affected by wind velocity, hence it is easy to be scattered on the pile of iron ore (Faschingleitner and Höflinger, 2011). Therefore, the dust suppression efficiency for conventional sprinkler technology is more favorable for large dust particles (i.e., TSP) and can achieve higher dust suppression efficiency at low wind velocity, high-angle spraying, and intermittent water supply as depicted in Fig. 6(b). It concludes that the dust suppression efficiency under high-angle spraying > low-angle spraying; that of low wind velocity > high wind velocity; and that of intermittent water supply mode $>$ continuous water supply mode. The optimal operating parameters for conventional sprinklers are low wind velocity, high-angle spraying, and intermittent water supply. At high-angle spraying, large droplets fall on the surface of the iron ore pile, whereby they can prolong the drying time and thus increase the dust suppression efficiency. The optimal operating parameters are also similar to previous investigation on coal pile, but its suppression efficiency of fugitive dust emitted from coal pile (76\%) is higher than that from iron ore pile (74\%) (Yen et al., 2021).

\subsection{Response Time for Dust Suppression Methods}

To determine how long it takes for the dust suppression methods to take effect, a portable dust particle monitor is applied to in-situ measure the concentrations of $\mathrm{PM}_{1}, \mathrm{PM}_{2.5}, \mathrm{PM}_{4}, \mathrm{PM}_{7}$, $\mathrm{PM}_{10}$ and TSP at the downwind side of the iron ore pile in the interval of $15 \mathrm{~min}$. As illustrated in Fig. 7(a), water mist generation technology under continuous water supply mode at high and low wind velocities can quickly reduce the concentration of fugitive dust within 45 and $60 \mathrm{~min}$, respectively. Thereafter, the dust concentration increases gradually, which is suspected to be caused by the weather in the region surrounding the test plant. High air temperatures outside coupled with the continuously blowing wind caused by the industrial fans at the blowing wind velocity of 3 or $10 \mathrm{~m} \mathrm{~s}^{-1}$, the moisture on the surface of the stockpile rises (Gladtke et al., 2009).

Fig. 7(a) shows that the concentrations of fugitive dust vary with wind speed under the intermittent water supply, whereby high and low wind velocities can quickly reduce the concentration of dust particles. However, unlike continuous water supply, there was no increase in the concentration of dust particles at 45 and $60 \mathrm{~min}$, despite the hot weather and wind driven by the industrial fans. Therefore, intermittent water supply is more favorable for dust suppression while compared to continuous water supply. Further investigation on the causes for this phenomenon is required in the future studies.

Fig. 7(b) illustrates the trend of dust concentration at the high and low wind velocities under high-angle sprinkling. It shows that at high and low wind velocities the re-suspended dust particles can be reduced and further deter repeat re-suspension after the spraying period. It is attributed 

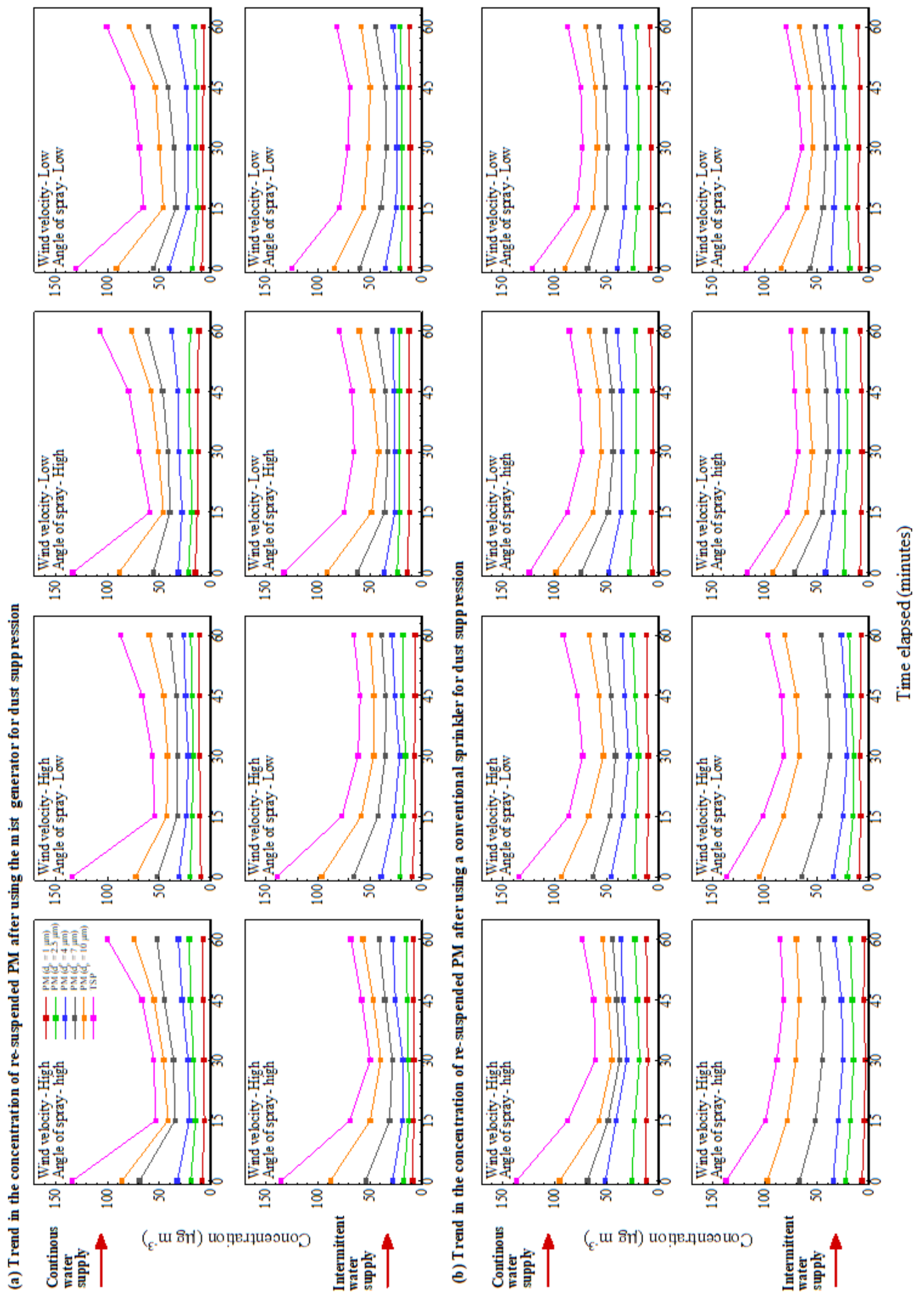

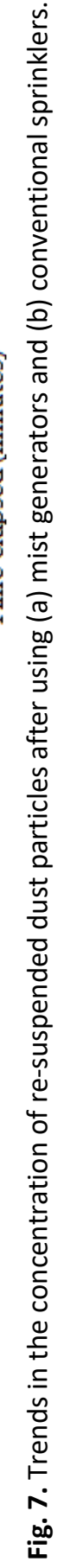


to the difficulty of evaporation associated with water droplets that fall on the iron ore piles. As shown in Fig. $7(b)$, the trend of dust concentration at the high and low wind velocities under low-angle sprinkling can reduce the concentration of dust particles, but at $45 \mathrm{~min}$, the dust concentration appears to increase gradually. It indicates that under low-angle sprinkling the droplets are unable to cover the entire surface area of iron ore pile adequately. Therefore, the use of high-angle sprinkling technology achieves higher dust suppression efficiencies compared to low-angle sprinkling. Further research is necessary to determine the optimal water volume control for high-angle sprinkling to attain the highest dust suppression efficiencies. However, the main drawback for both methods of spraying for dust suppression is failure of dust laden airstream to hit the spray and therefore ultimately unable to capture the dust (Gospodarek, 2010).

\subsection{Effects of Surfactants}

As depicted in Fig. 8, when the mass ratio of surfactant to water is 0.024 , the suppression efficiencies of TSP, $\mathrm{PM}_{10}$, and $\mathrm{PM}_{2.5}$ are $90.9 \%, 89.5 \%$, and $89.0 \%$, respectively. While, when the ratio surfactant to water was 0.022 , the suppression efficiencies of TSP, $\mathrm{PM}_{10}$, and $\mathrm{PM}_{2.5}$ are $89.7 \%, 86.7 \%$, and $86.5 \%$, respectively. When pure water is applied as the wetting agent under the same test conditions, the suppression efficiency of TSP, $\mathrm{PM}_{10}$, and $\mathrm{PM}_{2.5}$ are $82.3 \%, 78.4 \%$, and $79.0 \%$, respectively. This reveals that adding enough surfactant to water could effectively increase the dust suppression efficiency by $7.4 \%-11.1 \%$, which concurs quite well with previously published literature (Xu et al., 2018), since surfactants can improve the wetting capability of water by reducing the surface tension of water. The coal dust suppression efficiency which was $47 \%$ using pure water was improved to $63 \%$ with $0.2 \%$ Sodium Dodecylbenzene Sulfonate Surfactant (anionic) and to $57 \%$ with $0.2 \%$ Triton $X$ (non-ionic) surfactant. However, that was not the case for Cetrimonium bromide (cationic surfactant), whose suppression efficiency was $41 \%$. Surfactants improve the agglomeration rate of irregularly shaped dust particles hence minimizing the effect from the wind (Copeland and Kawatra, 2005). This suggests the importance of selecting appropriate wetting agent (Wang et al., 2019). Other surfactants such as sodium carboxymethyl cellulose solution (SCMS) have been investigated on dust suppression under the wind velocity of $15 \mathrm{~m} \mathrm{~s}^{-1}$. Dust suppression is improved from $94.3 \%$ without using surfactant to $99.2 \%$ with $0.1 \%$ of SCMS by mass (Borowski et al., 2020).

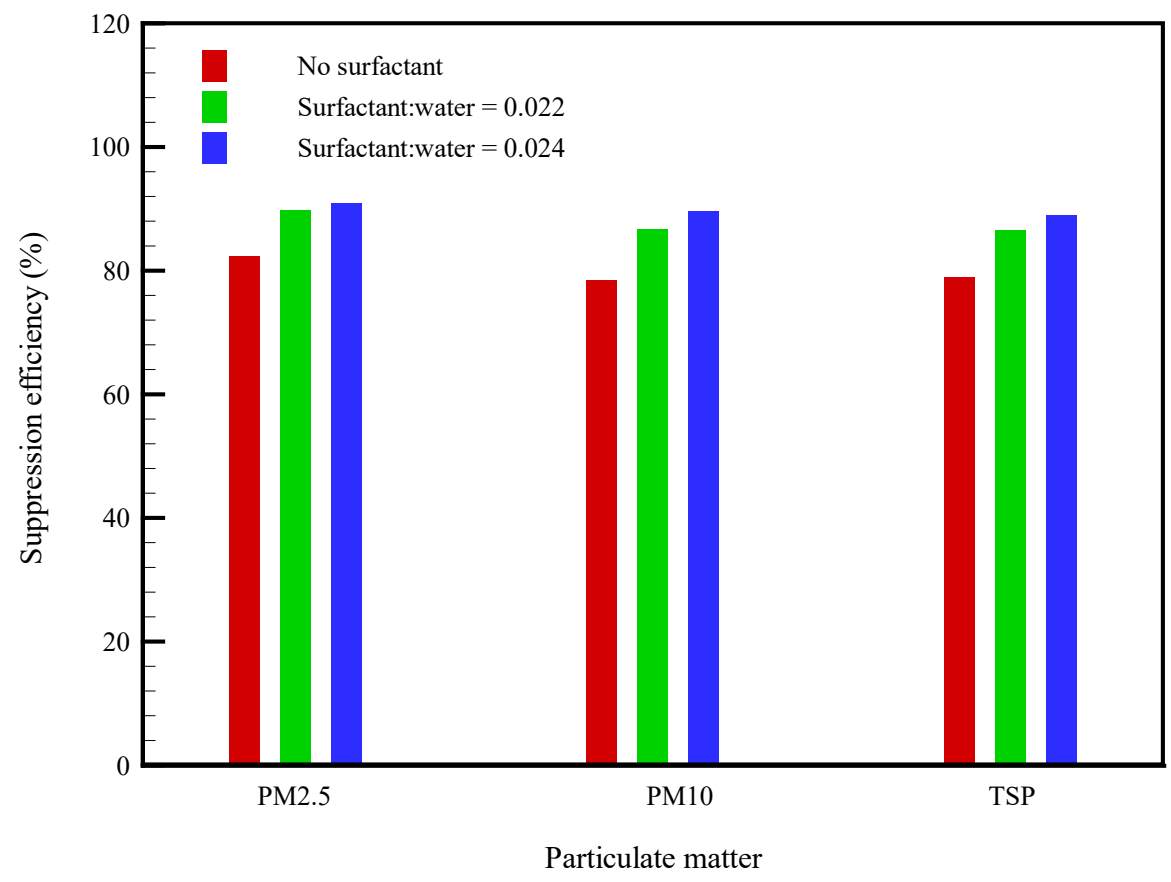

Fig. 8. Dust suppression efficiency for water spraying technology with the mass ratios of surfactant to water as the wetting agent at low wind velocity, high-angle spraying, and intermediate water supply. 
The concentrations of $\mathrm{PM}_{1}, \mathrm{PM}_{2.5}, \mathrm{PM}_{4}, \mathrm{PM}_{7}, \mathrm{PM}_{10}$, and TSP increase linearly with wind velocities in the range of 3-10 $\mathrm{m} \mathrm{s}^{-1}$ where, the regression lines can be expressed by the equation in the form of $Y=a X^{2}+b X+c$. The optimal operating parameters for dust suppression efficiency using mist generation technology are low wind velocity, low-angle spraying, and intermittent water supply, while those using conventional sprinkler are low wind velocity, high-angle sprinkling, and intermittent water supply. The average suppression efficiencies of TSP, $\mathrm{PM}_{10}$, and $\mathrm{PM}_{2.5}$ using the mist generation technology are $80.9 \%, 77.9 \%$, and $76.9 \%$ respectively, while those using the conventional sprinklers are $76.4 \%, 72.9 \%$, and $72.7 \%$. Overall, the mist generation technology is more effective than the conventional sprinkler technology for dust suppression over the iron ore piles. To prevent the interferences from outdoor environments and improve the test results of this investigation, the experiment could be designed and performed in an indoor testing field such as a factory building. Moreover, to reduce energy consumption, the technical design of the water mist nozzle's aperture size, water outlet pressure, spraying angle, and spraying area can be further improved. As an improvement to the dust suppression systems investigated here, the installation of miniature sensors for dust particles and anemometers in the raw material storage yard, combined with image recognition cameras and artificial intelligence system could serve as early warnings and assist in positioning the sites of dust re-suspension. This will ensure water spraying technologies are timely and economical. Applying the required amount of water only will save both water and energy consumption during dust suppression.

\section{ACKNOWLEDGEMENTS}

This study was performed under the auspices of Environmental Bioengineering and Chemical Analysis Section in New Materials Research and Development Department, China Steel Corporation (CSC) in Taiwan, Republic of China (ROC), under the contract number of 09T6D0009E. The authors are grateful to CSC for its financial support and administrative assistance in establishing the iron ore pile test field and providing raw materials for the suppression efficiency tests in order to accomplish this study.

\section{REFERENCES}

Borowski, G., Smirnov, Y., Ivanov, A., Danilov, A. (2020). Effectiveness of carboxymethyl cellulose solutions for dust suppression in the mining industry. Int. J. Coal Prep. Util. https://doi.org/10. 1080/19392699.2020.1841177

Chow, J.C., Watson, J.G., Ashbaugh, L.L., Magliano, K.L. (2003). Similarities and differences in $\mathrm{PM}_{10}$ chemical source profiles for geological dust from the San Joaquin Valley, California. Atmos. Environ. 37, 1317-1340. https://doi.org/10.1016/S1352-2310(02)01021-X

Chow, J.C., Watson, J.G., Kuhns, H., Etyemezian, V., Lowenthal, D.H., Crow, D., Kohl, S.D., Engelbrecht, J.P., Green, M.C. (2004). Source profiles for industrial, mobile, and area sources in the Big Bend Regional Aerosol Visibility and Observational study. Chemosphere 54, 185208. https://doi.org/10.1016/j.chemosphere.2003.07.004

Copeland, C.R., Kawatra, S.K. (2005). Dust suppression in iron ore processing plants. Min. Metall. Explor. 22, 177-191. https://doi.org/10.1007/BF03403321

Cullinan, P., Reid, P. (2013). Pneumoconiosis. Primary Care Respir. J. 22, 249-252. https://doi.org/ 10.4104/pcrj.2013.00055

Faschingleitner, J., Höflinger, W. (2011). Evaluation of primary and secondary fugitive dust suppression methods using enclosed water spraying systems at bulk solids handling. Adv. Powder Technol. 22, 236-244. https://doi.org/10.1016/j.apt.2010.12.013

Fu, S.C., Chao, C.Y.H., So, R.M.C., Leung, W.T. (2013). Particle resuspension in a wall-bounded turbulent flow. J. Fluids Eng. 135, 041301. https://doi.org/10.1115/1.4023660

Ghose, M.K., Majee, S.R. (2002). Assessment of the status of work zone air environment due to opencast coal mining. Environ. Monit. Assess. 77, 51-60. https://doi.org/10.1023/A:1015719625745 
Gladtke, D., Volkhausen, W., Bach, B. (2009). Estimating the contribution of industrial facilities to annual $\mathrm{PM}_{10}$ concentrations at industrially influenced sites. Atmos. Environ. 43, 4655-4665. https://doi.org/10.1016/j.atmosenv.2009.04.063

Gospodarek, J. (2010). Fluid Dynamical Analysis of Encased Dust Systems with Implemented TwoPhose Nozzle Sprays for the Purpose of Fugitive Dust Supression. PhD Thesis.

Heinrich, J., Peters, A., Wichmann, H.E., Grote, V. (2002). Health impact of exposure to suspended particulate matter Epidemiology of long-term effects. Umweltmed. Forsch. Prax. 7, 91-99.

Ho, K.F., Lee, S.C., Chow, J.C., Watson, J.G. (2003). Characterization of $\mathrm{PM}_{10}$ and $\mathrm{PM}_{2.5}$ source profiles for fugitive dust in Hong Kong. Atmos. Environ. 37, 1023-1032. https://doi.org/10.101 6/S1352-2310(02)01028-2

Humbal, C., Gautam, S., Trivedi, U. (2018). A review on recent progress in observations, and health effects of bioaerosols. Environ. Intl. 118, 189-193. https://doi.org/10.1016/j.envint.201 8.05.053

Khan, M.F., Shirasuna, Y., Hirano, K., Masunaga, S. (2010). Characterization of $\mathrm{PM}_{2.5}, \mathrm{PM}_{2.5-10}$ and $P M_{>10}$ in ambient air, Yokohama, Japan. Atmos. Res. 96, 159-172. https://doi.org/10.1016/j.a tmosres.2009.12.009

Kim, C.J., Sohn, C.H. (2016). Effects of wind barrier design and closed coal storage on spontaneous ignition of coal stockpiles. J. Loss Prev. Process Indust. 40, 529-536. https://doi.org/10.1016/ j.jp.2016.02.009

Kim, S., Kim, J., Choi, I., Li, H., Kang, J.H., Eo, H.J. (2020). Estimating fugitive particle emission from coal storage yard of thermal power plant using the flux-gradient method. Atmos. Environ. 243, 117860. https://doi.org/10.1016/j.atmosenv.2020.117860

Krishnan, A., Shalu, R., Sandeep, S., Jithin, S., Thomas, L., Panicker, S.T. (2020). A need-to-basis dust suppression system using wireless sensor network. 2020 IEEE Recent Advances in Intelligent Computational Systems (RAICS), India. pp. 207-212. https://doi.org/10.1109/RAICS 51191.2020.9332515

Lin, C.H., Lai, C.H., Peng, Y.P., Wu, P.C., Chuang, K.Y., Yen, T.Y., Xiang, Y.K. (2019). Comparative health risk of inhaled exposure to organic solvents, toxic metals, and hexavalent chromium from the use of spray paints in Taiwan. Environ. Sci. Pollut. Res. 26, 33906-33916. https://doi.org/10.1007/s11356-018-2669-8

Lu, C.C., Yuan, C.S., Li, T.C. (2017). How aeolian dust deteriorate ambient particulate air quality along an expansive river valley in southern Taiwan? A case study of typhoon doksuri. Aerosol Air Qual. Res. 17, 2181-2196. https://doi.org/10.4209/aaqr.2017.08.0257

Lu, C.C., Shen, H.Z., Li, T.C., Yuan, C.S. (2018). Influences of natural and anthropogenic particles on ambient particulate air quality during typhoon season: From Bashi Channel to Kaoping River Valley. AtScL 19, e819. https://doi.org/10.1002/asl.819

McKenna-Neuman, C., Nickling, W.G. (1989). A theoretical and wind tunnel investigation of the effect of capillary water on the entrainment of sediment by wind. Can. J. Soil Sci. 69, 79-96. https://doi.org/10.4141/cjss89-008

Ravi, S., D'Odorico, P., Breshears, D.D., Field, J.P., Goudie, A.S., Huxman, T.E., Li, J., Okin, G.S., Swap, R.J., Thomas, A.D., Van Pelt, S., Whicker, J.J., Zobeck, T.M. (2011). Aeolian processes and the biosphere. Revs. Geophy. 49, RG3001. https://doi.org/10.1029/2010RG000328

Richardson, C., Rutherford, S., Agranovski, I.E. (2019). Open cut black coal mining: Empirical verification of $\mathrm{PM}_{2.5}$ air emission estimation techniques. Atmos. Res. 216, 151-159. https://doi.org/10.1016/j.atmosres.2018.10.008

Sweeney, M.R. (2020). Dust Emission Processes, in: Reference Module in Earth Systems and Environmental Sciences, Elsevier. https://doi.org/10.1016/B978-0-12-818234-5.00015-8

Wang, P., Tan, X., Zhang, L., Li, Y., Liu, R. (2019). Influence of particle diameter on the wettability of coal dust and the dust suppression efficiency via spraying. Process Saf. Environ. Prot. 132, 189-199. https://doi.org/10.1016/j.psep.2019.09.031

Wang, Y., Jiang, Z. (2021). Research on mine cleaner production based on high wettability spray control dust pollution. Case Stud. Therm. Eng. 25, 100896. https://doi.org/10.1016/j.csite.202 1.100896

Watson, J.G., Chow, J.C. (2001). Source characterization of major emission sources in the Imperial and Mexicali Valleys along the US/Mexico border. Sci. Total Environ. 276, 33-47. https://doi.org/10.1016/S0048-9697(01)00770-7 
Xu, G., Chen, Y., Eksteen, J., Xu, J. (2018). Surfactant-aided coal dust suppression: A review of evaluation methods and influencing factors. Sci. Total Environ. 639, 1060-1076. https://doi.org/10.1016/j.scitotenv.2018.05.182

Yadav, M., Sahu, S.P., Singh, N.K. (2019). Multivariate statistical assessment of ambient air pollution in two coalfields having different coal transportation strategy: A comparative study in Eastern India. J. Cleaner Prod. 207, 97-110. https://doi.org/10.1016/j.jclepro.2018.09.254

Yen, P.H., Chen, W.H., Yuan, C.S., Tseng, Y.L., Lee, J.S., Wu, C.C. (2021). Exploratory investigation on the suppression efficiency of fugitive dust emitted from coal stockpile: Comparison of innovative atomizing and traditional spraying technologies. Process Saf. Environ. Prot. 154, 348-359. https://doi.org/10.1016/j.psep.2021.08.026

Zhang, H., Nie, W., Yan, J., Bao, Q., Wang, H., Jin, H., Peng, H., Chen, D., Liu, Z., Liu, Q. (2020). Preparation and performance study of a novel polymeric spraying dust suppression agent with enhanced wetting and coagulation properties for coal mine. Powder Technol. 364, 901-914. https://doi.org/10.1016/j.powtec.2019.10.082 